\title{
Poundings of seismically isolated buildings during strong earthquakes
}

\author{
P. Komodromos \\ Department of Civil \& Environmental Engineering, University of Cyprus, \\ Cyprus
}

\begin{abstract}
Seismic isolation reduces the induced seismic loads, particularly in low- to medium-rise buildings, by avoiding resonance, with the predominant frequencies of earthquake excitations, thanks to flexibility introduced at the isolation level. This earthquake resistant design approach significantly decreases the shear forces, interstory deflections, and floor accelerations of a building, avoiding damage of its structural and non-structural elements as well as damage of its contents. The size of the seismic gap, which must be provided around a seismically isolated building, in order to facilitate the expected large relative displacements at the isolation level, is usually finite, due to practical limitations, giving rise to the possibility of poundings of the building with adjacent structures during strong earthquakes. Therefore, understanding how the effectiveness of seismic isolation is affected from potential poundings of seismically isolated buildings with adjacent structures due to strong ground motions is vital. This research work aims to address this issue using numerical simulations and parametric studies in an effort to investigate how the maximum floor accelerations, story shear forces and interstory deflections of these buildings are affected by impacts and the relevant design parameters and conditions. Numerical simulations demonstrate that poundings may substantially increase floor accelerations, especially as the stiffness of the impact is increased, and, hence, may cause damage to the contents of a seismically isolated building, significantly reducing the effectiveness of seismic isolation. In addition to the presentation of results from parametric studies for some of the influencing conditions, the possibility of using bumpers, as a practical measure to mitigate the adverse effects from potential poundings, is considered.

Keywords: seismic isolation, poundings, impacts, seismic gap, bumpers.
\end{abstract}




\section{Introduction}

In recent years, there has been an increasing demand to minimize structural and non-structural damage, avoid functionality disruption and protect sensitive and expensive equipment in buildings even under extreme earthquake excitations, which is very difficult to achieve with conventional earthquake-resistant design. Seismic isolation [10], 11, 14, 18], an alternative design approach, introduces flexibility at the isolation level to avoid resonance, in low- to medium-rise buildings, with the predominant frequencies of earthquakes, and hence significantly reduces the induced floor accelerations and the possibility of damaging the contents of the building. In addition, interstory deflections are considerably reduced due to the almost rigid body motion of the superstructure, which is relatively very stiff compared to the flexibility of the isolation system, avoiding, or at least minimizing, structural and non-structural damage. The deformations are confined at the isolators, which are specifically designed to withstand several inelastic cycles of deformation and to accommodate the large relative displacements at the isolation level.

A practical limitation for the utilization of seismic isolation is the seismic gap (fig. 1.(a)) that must be provided around the building to facilitate the expected large relative displacements at the isolation level. Considering that there are often certain restrictions to the size of the provided seismic gap, a reasonable concern is the possibility of poundings of seismically isolated structures during strong earthquakes. Therefore, it is important to investigate that possibility and understand how the maximum floor accelerations and interstory deflections of seismically isolated buildings are affected by the various design parameters and conditions during impacts with adjacent structures.

Pounding incidences between fixed-supported buildings during strong earthquakes motivated pertinent research [1], 4-6, 8, 15-17], which led to reforms of relevant seismic-code provisions in order to mitigate the risks from poundings of fixed-supported structures. However, limited research studies [9], $12,13,19]$ have been conducted for poundings of seismically isolated buildings, which have different characteristics and a sizable seismic gap. Furthermore, there have been incidences of seismically isolated structures, such as the Los Angeles FCC building during the 1994 Northridge earthquake [13] that experienced poundings during strong earthquakes.

Therefore, this aspect of seismic isolation merits further research as it is important to understand the effects of potential poundings, considering that the dynamic characteristics and response of seismically isolated structures are quite different from those of fixed-supported structures. Poundings happen mostly due to the large relative displacements at the isolation level and not due to the deformation of the superstructure, as in the case of fixed-supported buildings. In addition, since seismic isolation is used in many cases in order to reduce the floor accelerations and the induced story shear forces, there may be stringent requirements that need to be satisfied and checked against the possibility of poundings and their consequences. 
The goal of this ongoing research work is to investigate how the effectiveness of seismic isolation is affected by poundings that may occur during strong earthquakes using parametric studies. The following section describes the simulation assumptions and approach that have been used and demonstrates the problem through the dynamic analysis of a typical 5-floor seismically isolated building under a strong earthquake. Next, simulation results are presented for some aspects that have been considered, such as the flexibility of the isolation system, the impact stiffness, the flexibility of the superstructure, and the size of the seismic gap. A discussion of potential benefits from employing collision-bumpers follows, and the paper closes with a brief summary of the conclusions.

\section{Problem and simulation approach}

A large number of simulations of seismically isolated buildings with a variety of characteristics have been conducted under a range of earthquake excitations in order to systematically investigate the influence of certain parameters and conditions on the maximum floor accelerations, interstory deflections, base shear forces and relative displacements at the isolation level, during poundings.

\subsection{Modeling of seismically isolated buildings considering poundings}

The governing equations of motion of a seismically isolated building (fig 1(a)), considering potential poundings, have the following general form, where $F_{I}, F_{D}$ and $F_{E}$ are the inertia, damping and elastic forces of the structure, while $F_{D}{ }^{C}$ and $F_{E}{ }^{C}$ are the damping and elastic contact forces, respectively:

$$
F_{I}+F_{D}+F_{D}{ }^{C}+F_{E}+F_{E}{ }^{C}=0
$$

The contact forces are non-zero whenever the relative displacements at the isolation level exceed the seismic gap, leading to poundings with the moat wall, which is assumed to move with the ground during an earthquake.
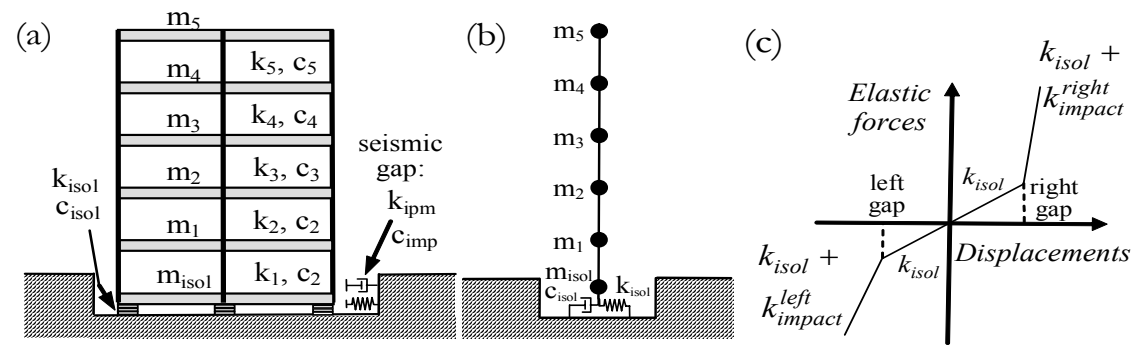

Figure 1: Modeling of a seismically isolated building (a) building and seismic gap (b) shear beam lumped-mass model (c) bilinear forcedisplacement relation due to impacts.

The superstructure is modeled as a shear beam with lumped masses at the floor levels (fig 1(b)), assuming that it remains elastic during an earthquake 
excitation, which is realistic considering the intention of seismic isolation to avoid inelastic deformations of the superstructure.

The inertia, damping and elastic forces depend on total accelerations, relative velocities and relative displacements, respectively. The damping and elastic forces at the isolation level depend on the type and mechanical characteristics of the isolation system, which in this work is simulated with a linearized model using an effective stiffness, $K_{\text {eff, }}$ and damping, $C_{\text {eff. Nevertheless, when }}$ poundings occur, the dynamic response of an isolated building is inherently nonlinear as a result of sudden changes of the stiffness due to impacts (fig 1(c)). In this study, a simplified model using equivalent contact springs and dashpots are employed to simulate poundings between a seismically isolated building and the moat wall.

The contact springs and dashpots are automatically formed as soon as impact is detected, kept as long as the building remains in contact with the moat wall and removed as soon as the bodies are detached from each other. The magnitude of the contact forces starts from zero, when the building and the moat wall first come in contact, and increases as they "interpenetrate" each other up to a maximum value and then start decreasing and eventually becomes equal to zero when they detach from each other. Some overlapping of the building with the moat wall is allowed, which is justified by the deformability of the wall. Dashpots are used at contact points parallel to the contact springs in order to model the energy dissipated during impact either in the form of local deformations or stress waves that will be generated upon impact.

Based on the above assumptions, specialized software has been specifically developed in order to perform efficient dynamic simulations of seismically isolated buildings during poundings. The developed software utilizes advances in computing and software engineering, such as Java technologies [4], taking into account the significant advantages that these technologies offer.

\subsection{Practical application}

A 5 -story building has been considered under the following three different circumstances: (a) as fixed-supported, (b) as seismically isolated without the possibility of impacts, and (c) as seismically isolated with a $0.10 \mathrm{~m}$ seismic gap, to illustrate the pounding effects on the response of a seismically isolated building. In particular, the building has 5 floors, each having a 400 tons mass and $1 \mathrm{GN} / \mathrm{m}$ stiffness $\left(T_{I}=0.44 \mathrm{~s}\right)$, while in the case of being seismically isolated it has an additional 500 tons mass at the isolation level and a $30 \mathrm{MN} / \mathrm{m}$ effective stiffness $\left(T_{I}=1.85 \mathrm{~s}\right)$. Rayleigh damping ratio is assumed defining $5 \%$ and $15 \%$ damping ratios for the fixed-supported and the seismically isolated buildings, respectively. The impact stiffness is assumed to be $k_{i m p}=500 \mathrm{MN} / \mathrm{m}$, and the damping coefficient $C_{i m p}=1 M N \mathrm{sec} / \mathrm{m}$.

For each of these three cases, a non-linear dynamic analysis of the building is performed, using an explicit direct integration of the equations of motion, for the El-Centro S00E component scaled to have a $P G A=0.5 g$. 
The results confirm that the interstory deflections and, therefore, the story shear forces increase in the case of a seismically isolated building when impacts occur (fig 2(c) vs. fig 2(b)). However, the interstory deflections of a fixed supported building (fig 2.(a)) are still much higher than those of the seismically isolated building even when poundings occur.

Obviously, the large relative displacement at the isolation level is reduced when there is a finite seismic gap with size less than the relative displacement at that level. In this case it is reduced from $U_{\max }^{i s o l}=155 \mathrm{~mm}$, in the no-impact case, to $U_{\max }^{i s o l}=117 \mathrm{~mm}$, in the case of limited seismic gap, which leads to poundings with the moat wall. The excess of the width of the seismic gap by the isolated building is allowed considering the expected deformations of the moat wall.

(a)

Fixed-supported 5-floor building

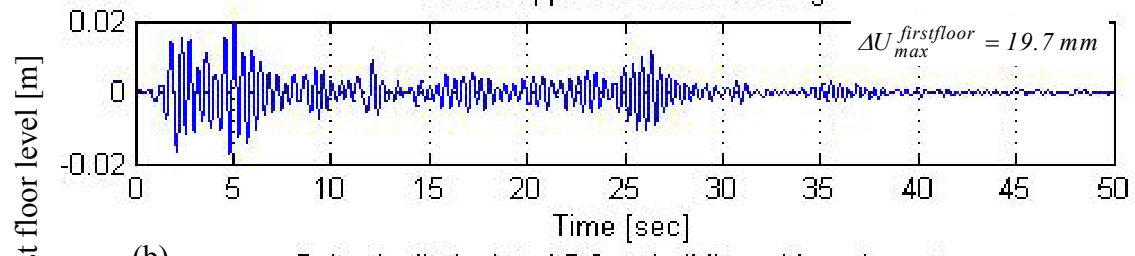

(b)

Seismically isolated 5 -floor building with no impact

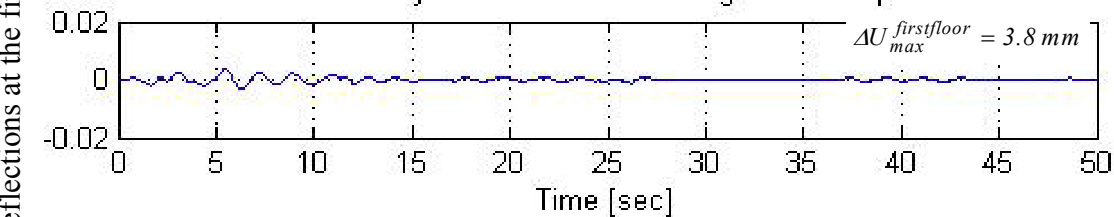

(c) Seismically isolated 5-floor building with impact (gap=0.10m)

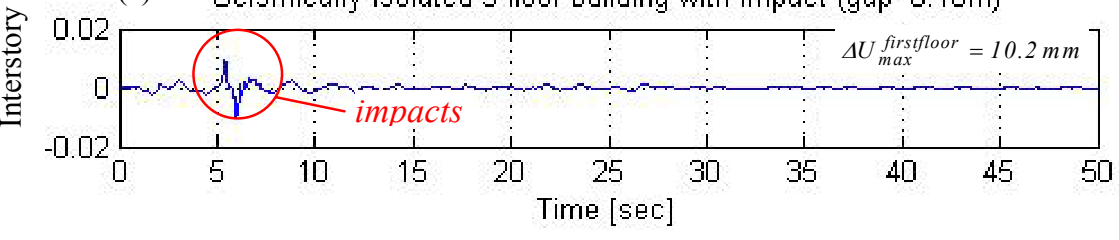

Figure 2: Interstory deflections of the first floor during the El-Centro S00E scaled to $P G A=0.5 \mathrm{~g}$ (a) fixed-supported building (b) seismically isolated building without impacts (c) seismically isolated building with impacts $\left(\right.$ gap left $_{\text {legap }}$ right $\left.=0.10 \mathrm{~m}\right)$.

Comparing the absolute floor accelerations of the building during the same excitation, the influence of poundings in the response of a seismically isolated building are much more pronounced as the peak acceleration at the isolation level (fig 2(c)) is 4 times more than the maximum acceleration at the top floor of the same building without any pounding incidence (fig 2(c)), approaching the magnitude of the top floor acceleration of the fixed-supported building. In addition, due to the poundings at the isolation level the seismically isolated structure may experience maximum floor accelerations at the isolation instead of the top floor of the building, changing the mode of deformation. 
(a)

Fixed-supported 5-floor building

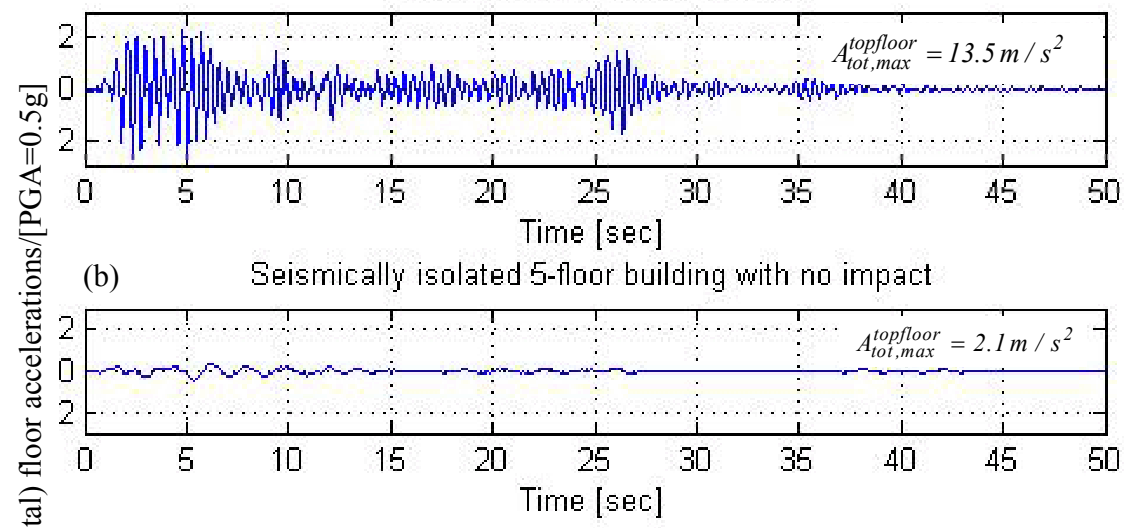

(c) Seismically isolated 5-floor building with impact (gap=0.10m)

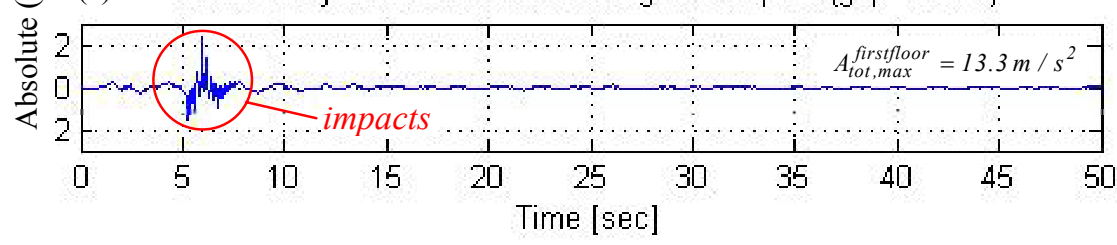

Figure 3: Absolute floor accelerations during the El-Centro S00E scaled to $P G A=0.5 \mathrm{~g}$ : (a) top floor of fixed supported building (b) top floor of seismically isolated building without impact (c) isolation-level of seismically isolated building with impact.

\section{Parametric studies and numerical results}

Simulation results of seismically isolated buildings using single degree of freedom (SDOF) systems with the equivalent stiffness of the isolation system and the total mass of the superstructure are very close to results using more refined models, such as multi degree of freedom (MDOF) systems as long as there are no pounding incidences. This is evident from the response of its fundamental eigenmode and the almost rigid body motion of the superstructure. However, when poundings occur, higher eigenmodes are excited, their contribution can no longer be assumed insignificant, and simulations need to be performed using MDOF systems in order to more accurately capture the consequences of impact. The following paragraphs present results from the ongoing research, which concern only some of the many influencing parameters and conditions that should be taken into account.

\subsection{Effect of the flexibility of the isolation system}

The flexibility of the isolation system for a typical 5-story building is varied in order to obtain seismically isolated buildings with fundamental periods in the range from 1.0 to $5.0 \mathrm{~s}$. Each of these MDOF systems is simulated for the El- 
Centro S00E component, scaled to $P G A=0.5 \mathrm{~g}$, considering three different gap sizes: $10 \mathrm{~cm}, 15 \mathrm{~cm}$ and $\infty$, equal on both sides of the building.

Considering that, for the same excitation, the corresponding fixed-supported building with a fundamental period of $0.44 \mathrm{~s}$ experiences a maximum interstory deflection of $19.7 \mathrm{~mm}$, a maximum total acceleration of $13.5 \mathrm{~m} / \mathrm{s}^{2}=2.76 \times P G A$, and a maximum base shear force of $19.7 \mathrm{MN}$, which approximates the weight of the structure, the following graph presents the maximum interstory deflections, maximum absolute floor accelerations and the maximum base shear forces of seismically isolated systems as the flexibility of the isolation system varies, with and without poundings.

(a)

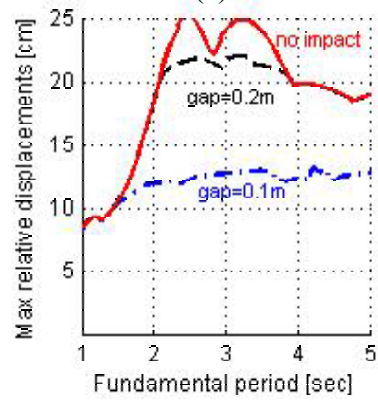

(b)

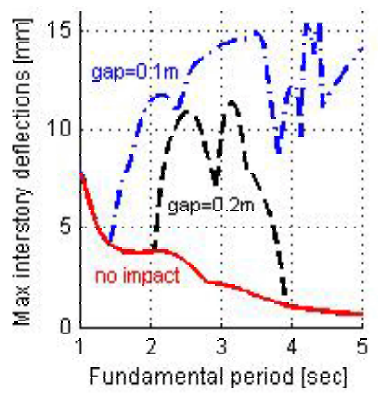

(c)

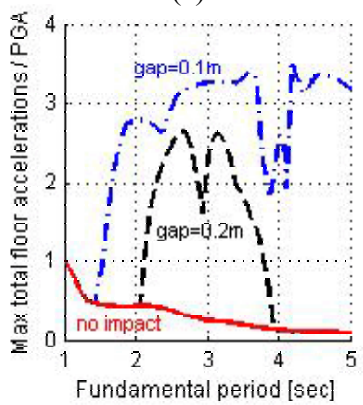

Figure 4: Response of seismically isolated MDOF systems with varying stiffness of the isolation system, with and without impact, for the El-Centro S00E scaled to $P G A=0.5 \mathrm{~g}$.

In most cases although the interstory deflections and, consequently, the corresponding story shear forces increase due to poundings, they remain relatively low compared to the values of the corresponding fixed-supported buildings. It is evident that the major consequence of poundings on a seismically isolated building is the substantial increase of the floor accelerations and inertia forces, which can be detrimental for the contents of the building, especially if the latter are sensitive to accelerations.

\subsection{Effect of the impact stiffness and damping}

Considering the 5-story building that has already been defined, the impact stiffness $K_{i m p}$ is varied from a small fraction up to 2 times the stiffness of a story of the superstructure. As the impact stiffness varies, the damping coefficient $C_{i m p}$ is adjusted in proportion to the square root of the ratio of the change of the impact stiffness according to formulas that express the damping coefficient [2]. These systems are simulated for different sizes of the seismic gap and the maximum values of the relative displacements at the isolation level, the maximum values of total floor accelerations normalized with the $P G A$ and the maximum story shear forces normalized with the total weight, $w$, of the structure are presented in fig. 5 . 
(a)

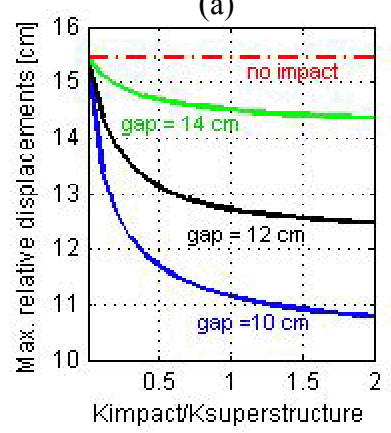

(b)

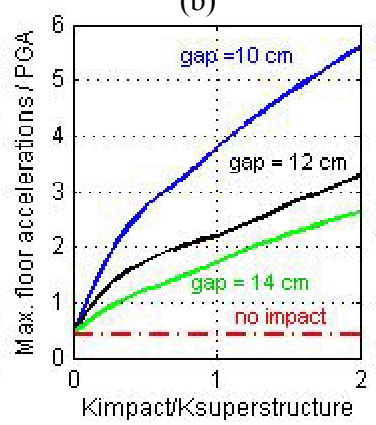

(c)

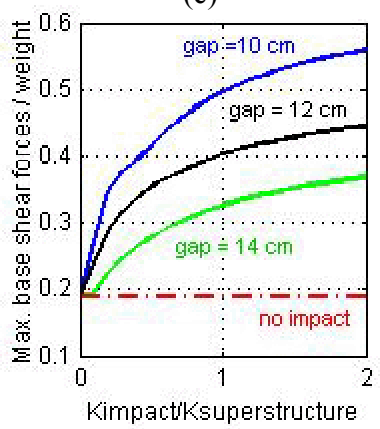

Figure 5: Response of seismically isolated MDOF systems with varying impact stiffness and damping, for various gap sizes, under the El-Centro S00E scaled to $P G A=0.5 \mathrm{~g}$.

Increasing the impact stiffness the relative displacements at the isolation level (fig 5(a)) approach the size of the seismic gap, but the maximum floor accelerations (fig 5(b)) and consequently the inertia forces increase substantially due to poundings and may become much higher than what the building would experience without seismic isolation. The maximum interstory deflections and the base shear forces (fig 5(c)) also increase with the impact stiffness, but remain much lower than what a corresponding fixed-supported structure would experience. The substantial increase of the floor accelerations with the impact stiffness indicates that the latter should not be more than a fraction of the stiffness of the superstructure, especially when the contents of the building are very sensitive to large accelerations.

(a)

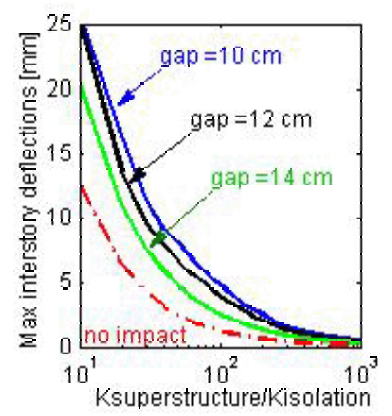

(b)

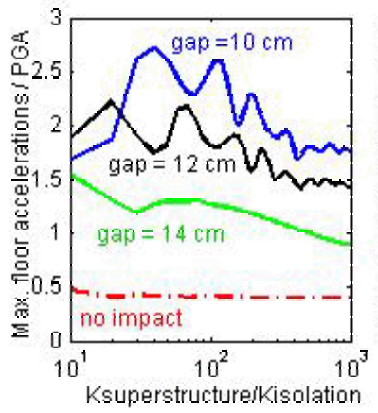

(c)

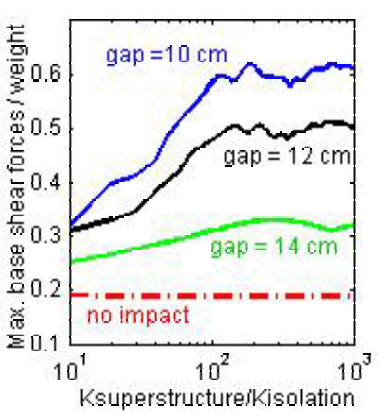

Figure 6: Response of seismically isolated MDOF systems with varying stiffness of the superstructure, for various gap sizes, under the El-Centro S00E scaled to $P G A=0.5 \mathrm{~g}$. 


\subsection{Effect of the superstructure's stiffness}

Varying the stiffness of the superstructure and examining different sizes of the seismic gap, while maintaining other factors constant indicates that by increasing the flexibility of the superstructure the interstory deflections (fig 6(a)) are significantly increased, the total floor accelerations (fig 6(b)) are slightly increased, while the story shear forces (fig 6(c)) are reduced.

\section{Impact mitigation measures}

A potential practical measure to alleviate the detrimental effects of poundings could be the installation of flexible material with damping properties that would protrude at certain locations in order to act as collision bumpers. Adding such material, which can simply be pieces of elastomeric compounds, to the moat wall or to the seismically isolated building can smooth the sudden changes of the stiffness during poundings and therefore prevent, to some extent, the acceleration peaks due to impacts.

The building under consideration in the previous paragraphs, can be used as a practical example to examine the effect of using bumpers, assuming that a gap of $12 \mathrm{~cm}$ is available between the building and the stiff moat wall. Instead of letting the building collide with the moat wall when the $12 \mathrm{~cm}$ gap is exceeded, a softer material with impact stiffness and damping $10 \%$ and $90 \%$, respectively, of the corresponding values for the moat wall is alternatively considered. The relation between the relative displacements and the sum of the elastic and impact forces at the isolation level becomes trilinear in this case as it is shown in fig $7(\mathrm{a})$.

(a)

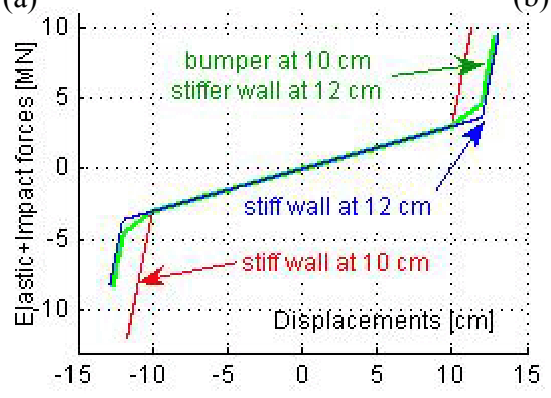

(b)

\begin{tabular}{|r|c|c|c|}
\hline Gap [cm]: & 10 & $10 / 12$ & 12 \\
\hline $\begin{array}{c}\text { Max. relative } \\
\text { displacements [cm] }\end{array}$ & 11.7 & 12.9 & 13.1 \\
\hline $\begin{array}{c}\text { Max. interstory } \\
\text { deflections [mm] }\end{array}$ & 10.2 & 8.6 & 8.7 \\
\hline $\begin{array}{c}\text { Max. floor accelerations } \\
\text { [PGA] }\end{array}$ & 2.7 & 1.4 & 1.7 \\
\hline Max. inertia force [MN] & 5.9 & 3.1 & 3.7 \\
\hline Max. elastic force [MN] & 10.2 & 8.6 & 8.7 \\
\hline Max. impact force [MN] & 8.4 & 5.6 & 5.6 \\
\hline
\end{tabular}

Figure 7: (a) Displacements vs. sum of the elastic and impact forces at the isolation level of a seismically isolated MDOF system with and without bumpers for $10 \mathrm{~cm}$ and $12 \mathrm{~cm}$ gap sizes, under the ElCentro S00E scaled to $P G A=0.5 \mathrm{~g}$ (b) absolute floor accelerations at the isolation and top floor for the three cases. 
The 5 -story building is analyzed again for the El-Centro S00E component, scaled to $P G A=0.5 \mathrm{~g}$, considering three cases: (a) a seismic gap of $10 \mathrm{~cm}$ (b) a $2 \mathrm{~cm}$ bumper at $10 \mathrm{~cm}$ (c) a seismic gap of $12 \mathrm{~cm}$. The peak values of the relative displacements at the isolation level, the interstory deflections, the floor accelerations, and the maximum inertia, elastic and impact forces (fig 7(b)) demonstrate the positive effect of the presence of the bumper, which is also shown the absolute floor accelerations at the isolation level and the top floor for the three cases (fig 8(a)-(c)). In practice, the material of the bumper should be selected to have such properties that would optimize the benefits from the presence of the bumper during poundings.
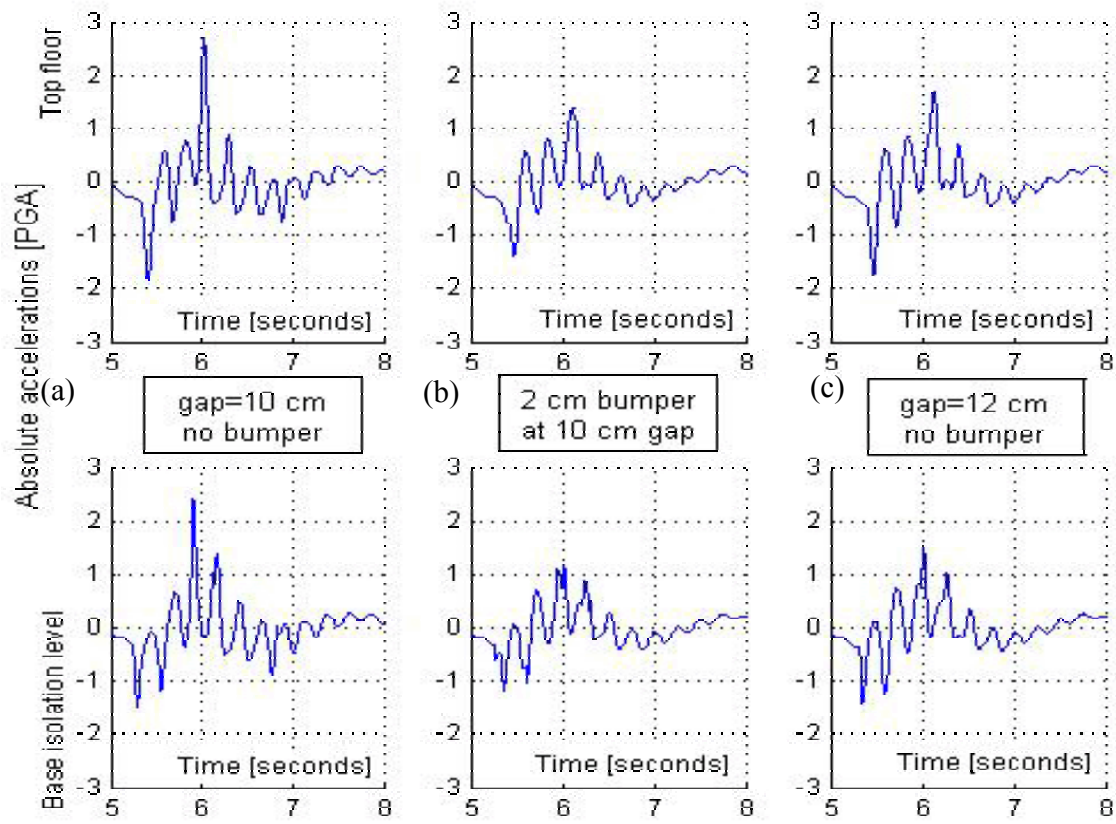

Figure 8: Absolute floor accelerations at the isolation level and at the top floor for a seismically isolated MDOF system, under the El-Centro S00E scaled to $P G A=0.5 \mathrm{~g}$, with: (a) $10 \mathrm{~cm}$ gap (b) a bumper between $10 \mathrm{~cm}$ and $12 \mathrm{~cm}$ (c) $12 \mathrm{~cm}$ gap.

\section{Conclusions}

The paper discusses the effects of poundings on seismically isolated buildings during strong earthquakes in an effort to gain insight into this complicated problem, considering only some of the many influencing parameters. It is shown that the effectiveness of seismic isolation can be significantly affected, especially when sensitive equipment is housed in a seismically isolated building, due to the substantially increased floor accelerations. In addition, due to poundings other 
modes of deformations are excited resulting in higher interstory deflections instead of the almost rigid body motion of the superstructure, which is accomplished using seismic isolation. Understanding the consequences of potential poundings of seismically isolated buildings with adjacent structures is essential in order to rationally take into account the possibility of impact, which realistically cannot be excluded.

The potential advantages of using bumpers have also been discussed as a measure to alleviate the negative effects of poundings. Bumpers in the form of pieces of flexible viscous material, such as elastomeric compounds, can be attached at particular locations in the perimeter of the building as shock absorbers to mitigate the consequences of potential collisions with adjacent structures and avoid the acceleration spikes that are observed during impacts.

\section{References}

[1] Anagnostopoulos A (1988) "Pounding of buildings in series during earthquakes", Earthquake Engineering and Structural Dynamics, Vol. 16, pp. 443-456.

[2] Anagnostopoulos A (2004) "Equivalent viscous damping for modeling inelastic impacts in earthquake pounding problems", Earthquake Engineering and Structural Dynamics, Vol. 33, pp. 897-902.

[3] Bathe Klaus-Jurgen (1996) Finite Element Procedures, Prentice-Hall Inc., Eaglewood Cliffs, New Jersey.

[4] Bill Joy B., Steele G, Gosling J., and Bracha G. (2000), "The Java Language Specification", 2nd Edition, Addison-Wesley Pub Co.

[5] Chau KT, Wei XX (2001) "Poundings of structures modeled as non-linear impacts of two oscillators", Earthquake Engineering and Structural Dynamics, Vol. 30, pp. 633-651.

[6] Chau KT, Wei XX Guo X, Shen CY (2003) "Experimental and theoretical simulations of seismic poundings between two adjacent structures", Earthquake Engineering and Structural Dynamics, Vol. 32, pp. 537-554.

[7] Chopra AK (1995) "Dynamics of Structures", Prentice Hall, pp. 683-702.

[8] Davis RO (1992) "Pounding of buildings modeled by an impact oscillator", Earthquake Engineering and Structural Dynamics, Vol. 21, pp. 253-274.

[9] Dimova SL (2000) "Numerical problems in modeling of collision in sliding systems subjected to seismic excitations", Advances in Engineering Software, Vol. 31, pp 467-471.

[10] Kelly JM (1997) Earthquake Resistant Design with Rubber, SpringerVerlag, Second Edition.

[11] Komodromos P (2000), "Seismic Isolation for Earthquake-Resistant Structures", WIT Press.

[12] Malhotra PK (1997) "Dynamics of seismic impacts in base-isolated buildings", Earthquake Engineering and Structural Dynamics, Vol. 26, pp. 797-813. 
[13] Nagarajaiah S, Xiaohong S (2001) "Base-Isolated FCC Building: Impact Response in Northridge Earthquake", Journal of Structural Engineering, ASCE, Vol. 127, No. 9, pp. 1063-1075.

[14] Naeim F, Kelly JM (1999) "Design of Seismic Isolated Structures”, John Wiley \& Sons Inc.

[15] Pantelides CP, Ma X (1997) "Linear and nonlinear pounding of structural systems", Computers and Structures, Vol. 66, No. 1, pp. 79-92.

[16] Papadrakakis M, Apostolopoulou C, Zacharopoulos A, Bitzarakis S, (1996) "Three-dimensional simulation of structural pounding during earthquakes", Journal of Engineering Mechanics, Vol. 122, No 5, pp. 423-431.

[17] Penzien J (1997) "Evaluation of building separation distance required to prevent pounding during strong earthquakes", Earthquake Engineering and Structural Dynamics, Vol. 26, pp. 849-858.

[18] Skinner RI, Robinson WH, McVerry GH (1993) “An Introduction to Seismic Isolation”, DSIR Physical Sciences, Wellington, New Zealand, John Wiley \& Sons.

[19] Tsai HC (1997) "Dynamic analysis of base-isolated shear beams bumping against stops", Journal of Earthquake Engineering and Structural Dynamics, Vol. 26, pp. 515-528. 